\title{
Darwinism, Causality and the Social Sciences
}

\author{
by Geoffrey M. Hodgson
}

17 January 2004

Presented at the INEM meeting in Washington DC, January 2003;

Published in the Journal of Economic Methodology, 11(2), June 2004, pp. 175-94.

\author{
The Business School, University of Hertfordshire, Mangrove Road, Hertford, Hertfordshire SG13 8QF, UK \\ http://www.herts.ac.uk/business/esst/Staff/g-hodgson/hodgson.html \\ http://www.geoffrey-hodgson.ws \\ Address for correspondence: \\ Malting House, 1 Burton End, West Wickham, Cambridgeshire CB1 6SD, UK \\ g.m.hodgson@herts.ac.uk
}

KEY WORDS: Darwinism, ontology, causality, determinism, evolution, emergent properties

\author{
JEL classification: B41, B52
}

\begin{abstract}
Recently the degree to which 'evolutionary economics' does or should involve Darwinian principles has come under debate. This essay builds on previous arguments that Darwinism has a potentially wide application to socio-economic evolution, which does not involve biological reductionism. It is argued that at the core of Darwinism are presuppositions concerning causality and causal explanation. Contrary to widespread belief, these presuppositions do not downgrade or ignore human intentionality: they simply require that it too is in principle subject to causal explanation. Neither are these presuppositions 'deterministic' or 'mechanistic', at least by some prominent meanings of these terms. Furthermore, the presupposition of causal determination does not necessarily exclude or include stochastic or probabilistic determination.
\end{abstract}

\section{BIOGRAPHY}

Geoffrey Hodgson is a Research Professor at the University of Hertfordshire and was formerly Reader in Economics at the University of Cambridge. He is the author of Economics and Institutions (1988) and Economics and Evolution (1993). His recent publications include How Economics Forgot History (Routledge, 2001) and The Evolution of Institutional Economics (Routledge, 2004). 


\title{
Darwinism, Causality and the Social Sciences
}

\author{
by Geoffrey M. Hodgson ${ }^{1}$
}

The term 'evolutionary economics' describes a wide variety of views and approaches, some of which do not embrace ideas or analogies from biology. Even among those inspired by aspects of biology - most notably Richard Nelson and Sidney Winter (1982) - there is a reluctance to use the 'Darwinian' label. Darwinian ideas have been resisted in the social sciences, even among self-described 'evolutionary' thinkers (Hodgson, 2002). Some critics object that Darwinism excludes or downplays human intentionality, and is hence 'deterministic' or 'mechanistic'.

Nevertheless, the use of Darwinian mechanisms of variation, inheritance and selection is quite widespread among evolutionary economists. It is argued elsewhere that if the ideas of variation, inheritance and selection are carefully and appropriately defined then they have a potentially wide application to social and economic, as well as biological phenomena. Although the mechanisms of replication, selection and variety-creation are very different in the social and economic domains, they have sufficient in common at an abstract level. Hence, under specific conditions, a broad and general version of Darwinism may apply to all complex, open and evolving systems (Ritchie, 1896; Veblen, 1919; Campbell, 1965; Dawkins, 1983; Hodgson, 2002). This application does not itself involve biological reductionism, where all aspects of the evolving system are said to be explicable in biological terms alone. Neither is it merely a matter of analogy. ${ }^{2}$

In the light of the observations in the previous paragraph, it is the purpose of this paper to explore some of the philosophical implications of Darwinism for the social sciences. It concentrates more narrowly on questions of ontology, particularly concerning causality. Other implications of Darwinism for social evolution are explored elsewhere (Veblen, 1919; Hodgson, 2004). The principles of Darwinism adduced in this paper neither logically flow from, nor themselves imply, Universal Darwinism. However, the possibility of Universal Darwinism suggests that such principles might apply to the social sciences, as well as to biology. ${ }^{3}$

Ernst Mayr (1964, p. xviii) rightly remarked: 'It has taken 100 years to appreciate fully that Darwin's conceptual framework is, indeed, a new philosophical system.' The philosophical

\footnotetext{
1 This essay makes use of material from Hodgson (2004) and extends and modifies slightly the argument in Hodgson (2001b). The author is very grateful to Jack Vromen, anonymous referees and others for comments on earlier versions of this essay.
}

2 In this vein, Knudsen (2004) provides a useful generalization of the concept of selection. By contrast, Witt (2004) acknowledges the possibility of a generalized Darwinism but does not embrace this approach himself.

${ }^{3}$ Universal Darwinism is discussed in Hodgson (2001a, 2002, 2003, 2004). 
aspects of Darwinism are now more widely appreciated. A survey of about one thousand academic philosophers organised by the Philosopher's Magazine put Darwin's Origin of Species as the third most important book in philosophy ever, after Plato's Republic and Kant's Critique of Pure Reason. ${ }^{4}$ A full appreciation of the philosophical implications of Darwinism for social science is now due.

\section{Meanings of Causality}

Aristotle identified four types of causality: the formal, material, efficient and final. His notion of 'cause' was somewhat broader than the modern meaning. It included broad assertions of the nature, location, form and material constitution of a phenomenon, in terms of 'formal' or 'material' 'causes'. In much modern usage, a narrower sense of the word is invoked: causes are always taken to mean the specific factors leading to an effect. As Jochen Runde (1998, p. 154) puts it: 'a cause of an event [includes] anything that contributes, or makes a difference, to the realisation of that event in one or more of its aspects.'

Within this narrower and more dynamic class of 'cause', Aristotle distinguished between 'efficient' and 'final' causality. Efficient causality is similar to the concept of causality in the modern natural sciences. The word 'efficient' here does not necessarily refer to an optimal (or any other particular type of) outcome. It simply means capable of having an effect. Final causality, or 'sufficient reason', is teleological in character: it is directed by an intention, purpose or aim. Hence, within this narrower notion of a cause, Aristotle promoted a causal dualism.

This distinction persists in modern thought, where the natural sciences embrace descriptions of cause and effect involving matter and energy, and the social sciences find their adequate causal fuel in human intentions or purposes. The compartmentalisation of the natural from the social sciences encourages a form of dualism with two different conceptions of cause. $^{5}$

Here the attempt at reconciliation proceeds in materialist and naturalist terms. The modern natural sciences admit no cause that does not involve the rearrangement or transformation of physical matter or energy. All such causes involve movements of matter and transfers of energy or momentum, as a necessary but not sufficient condition of it being a cause. All genuine causes are materialist causes, in that they satisfy this condition. Intentions can satisfy the materialist condition of causality if intentions are understood as involving transfers of matter or energy, including at the neural level. Indeed, any action or communication involves movements of matter and transfers of energy or momentum. However, notwithstanding the fact that they are caused, intentions themselves are causes.

In philosophy, the precise definition and logical form of a causal statement is highly complex and still unresolved (Sosa and Tooley, 1993; Salmon, 1998). The 'materialist'

\footnotetext{
4 The Guardian, 21 September 2001.

5 See Bunge (1980) and Stich (1996). P. S. Churchland (1986), P. M. Churchland (1984, 1989) and Rosenberg (1995) have critiqued the 'folk psychology' involved in explanations of human action wholly in terms of reasons and beliefs. For them, such explanations are a mere gloss on a much more complex neurophysiological reality. These critiques see traditional or dualistic explanations of human behaviour as being unable to explain adequately such phenomena as sleep, memory, learning, mental illness, or the effects of chemicals or drugs on our perceptions or actions.
} 
condition imposed here, however, is to some degree independent of this philosophical debate and, judging from the issues involved, is unlikely to be affected by its conclusion. Although, at least at the social level, we cannot understand causality completely in terms of identifiable material relations, nevertheless all relevant causal relations involve movements of matter and transfers of energy or momentum.

From this perspective, we may consider the additional Aristotelian category of causality in the teleological form of 'sufficient reason'. Any such cause is irrelevant unless it also involves such movements of matter and transfers of energy or momentum, including at the neurological level. It is central to Darwinism that intentionality must itself be capable of explanation in terms of such movements and transfers. Intentions are real and intentions are causes but intentions do not require an entirely different notion of causality. The causes of intentions and their causal effects have to be explained, in terms that include the important role of mental prefiguration and judgement. But these mental aspects also involve movements of matter and transfers of energy or momentum, within the brain. They are special causal mechanisms but not an entirely different (teleological) category of cause.

The fact that the sciences are still saddled - well over two millennia after Aristotle - with more than one version of causality, is rarely a subject for discussion. The wall between the natural and the social sciences has averted us from this question. Yet when dialogue does occur between the biologist and the social scientist then the problem emerges, even if its philosophical connotations are not fully understood.

The development of quantum physics - particularly in the so-called Copenhagen interpretation - has sometimes served as an excuse to relinquish a commitment to causal explanation in the terms outlined here. However, statistical determination, as expressed in probabilities, does not imply the absence of a cause. Charles Sanders Peirce gave the name 'tychism' to the doctrine of the probabilistic nature of causation, with objective chance as a propensity. However, even if outcomes are stochastic, statistical determination is still involved. Statistical determination or tychism does not mean indeterminacy. Accordingly, Mario Bunge (1959, pp. 14-17) has established that quantum physics does not necessarily lead to an abandonment of some standard principles of causal determination.

Furthermore, it is possible that quantum physics is consistent with a non-statistical version of causal determination. We may not be able to offer singular predictions of the motion of subatomic particles simply because of our ignorance of all the causes that bear upon them. As Bertold Brecht had a character explain in his play Me-Ti: 'Their movements are difficult to predict, or cannot be predicted, only because there are too many determinations, not because there are none.' The same may be true of the sub-atomic quanta. Albert Einstein and others were concerned about the abandonment of strict causation by the quantum physicist for some form of stochasticity, and remarked that he could not believe 'in a God who plays dice' and he had to retain faith in 'in complete law and order'. Consequently, Einstein et al. (1935) argued that explanations of quantum phenomena had to be completed by the addition of 'hidden variables' (Salmon, 1998, pp. 273-6). This issue remains controversial in physics (Cushing, 1994).

However, we now know that the non-linear systems addressed by chaos theory can simulate stochastic behaviour. Ian Stewart (1989) has thus conjectured that chaos theory can thereby bridge the gulf between the apparent randomness of the quanta and the operation of causal laws. The throw of a die leads to apparently random effects, but that does not rule out the outcome being a unique result of a specific combination of prior circumstances and events. Similarly, random number generators in computers use straightforward multiplication and 
numerical truncation to generate a series of (pseudo-) random numbers. Apparent statistical determinacy may be an aggregate outcome of stricter causal processes operating at lower, micro levels.

Concerning Darwinism, no ruling is necessary, or will be made here, over the admissibility or otherwise of statistical or stochastic determination. The minimum core ontological position maintained and defended here involves the principle of determinacy or universal causation (see below), and a commitment to a singular type of causation than can connect diverse domains. The principle of statistical determination is ruled neither out nor in. The rise of chaos and complexity theory, has given a recent fillip to Einstein's proposition that strict rather than statistical determination is everywhere at work. But it is not necessary to take a position on this here.

\section{Darwinism and Causality}

Darwin did not only proclaim that species had evolved, but also pointed to the causal mechanisms of evolution. For Darwin, science involved a commitment to causal explanations. Darwin's life work was marked by an ambition to extend the realm of causal explanation into areas that were deemed taboo by religious doctrine. Even before his theory of natural selection was fully formulated, Darwin considered that the origin of the human species, and its unique capacity for reflection and rational deliberation, could in principle be explained by science. In 1838 Darwin jotted in his 'Notebook C': 'Why is thought, being a secretion of the brain, more wonderful than gravity a property of matter? It is our arrogance, it our admiration of ourselves' (Barrett et al., 1987, p. 291). Darwin rejected explanations of natural phenomena in terms of design, to focus instead on the detailed physical or 'efficient' causes that had cumulated in the emergence of elaborate phenomena over long periods of time.

An important reason why Darwin delayed the completion and publication of his Origin of Species for twenty years, was for fear of hostility to his materialist philosophical views (Gould, 1978, pp. 21-7; Ruse, 1979, pp. 184-5). Nevertheless, his search for causal explanations permeates all his work. He was aware that his Origin of Species did not offer a complete causal account. For example, he referred to a profound ignorance of the mechanisms that led to variations in organisms (Darwin, 1859, p. 167). But he did not believe that variations emerged spontaneously, in the sense of being without a cause. Darwin (1859, p. 209) asserted that such 'accidental variations' must be 'produced by ... unknown causes' rather than embracing a notion of a spontaneous, uncaused event.

In his Descent of Man, Darwin (1871, vol. 1, p. 131) wrote similarly of 'a large class of variations which may be provisionally called spontaneous, for they appear, owing to our ignorance, to arise without any exciting cause.' Note that Darwin did not believe that the variations arose without a prior cause. He simply argued that 'owing to our ignorance' they 'appear' to be 'spontaneous'. In a later work Darwin (1883, vol. 2, p. 282) wrote: 'No doubt, each slight variation must have its efficient cause'. Even when the causal mechanism was elusive or unknown, he believed that it was the task of the scientist to attempt to discover it.

The frequent suggestion that Darwin's theory necessarily involves or implies a stochastic, tychist or probabilistic concept of causality is ungrounded. Darwin himself believed in a notion of causality that involved the transfers of physical matter or energy. He believed that relatively simple mechanisms of cause and effect could, given time and circumstances, lead to amazingly complex and varied outcomes. He relied on this intuition, rather than any notion of statistical or stochastic determination. But his doctrine would not be negated if causes were in 
fact stochastic. Within Darwinism, we can remain agnostic on the question of probabilistic, statistical, tychist or stochastic determination.

Darwin upheld that complex outcomes could be explained in terms of a detailed succession and accumulation of step-by-step causal mechanisms. Darwin (1859, p. 43) wrote of the supreme importance of 'the accumulative action of Selection'. Darwin's famous maxim, 'natura non facit saltum' (nature does not make leaps) was in part an appeal to this method of detailed, sequential causal explanation. In one of the several places in the Origin where he repeats this motto, Darwin (1859, p. 471) wrote: 'As natural selection acts solely by accumulating slight, successive, favourable variations, it can produce no great or sudden modification; it can act only by very short and slow steps.' Darwin did not simply argue that natural selection worked slowly, he also - and more importantly - upheld that each step was susceptible to causal explanation. ${ }^{6}$

This doctrine held, in particular, to the most sophisticated and complex outcomes of evolution, such as the eye and human consciousness. Darwin believed that such phenomena were capable of an evolutionary and causal explanation. Accordingly, there were neither sudden nor miraculous leaps in the evolution of human intentionality. Like all human attributes, they must have been prefigured in the species from which humans are descended. In this way the causal origin of these features is susceptible to explanation. Darwin (1859, p. 208) thus wrote: 'A little dose ... of judgement or reason often comes into play, even in animals very low in the scale of nature.' In a paper of 1874, Huxley (1894, vol. 1, pp. 236-7) elaborated and generalised Darwin's argument as the 'doctrine of continuity':

The doctrine of continuity is too well established for it to be permissible to me to suppose that any complex natural phenomenon comes into existence suddenly, and without being preceded by simpler modifications; and very strong arguments would be needed to prove that such complex phenomena as consciousness, first made their appearance in man. We know, that, in the individual man, consciousness grows from a dim glimmer to its full light, whether we consider the infant advancing in years, or the adult emerging from slumber and swoon. We know, further, that the lower animals possess, though less developed, that part of the brain which we have every reason to believe to be the organ of consciousness in man; ... [they] have a consciousness which, more or less distinctly, foreshadows our own.

In addition, Huxley had similar views to Darwin concerning causality and the aims of science. For Huxley the idea of uncaused and spontaneous event was absurd and unacceptable. Science was nothing less than an ongoing endeavour to reveal the causes behind phenomena. Huxley (1894, vol. 1, pp. 158-9) wrote:

any one who is acquainted with the history of science will admit, that its progress has, in all ages meant, and now, more than ever, means, the extension of the province of what we call matter and causation, and the concomitant gradual banishment from all regions of thought of what we call spirit and spontaneity.

Similarly, George Romanes - a friend of Darwin and Huxley - also insisted that Darwinism above all meant causal analysis. For Romanes (1893, p. 5), taxonomy and the accumulation of facts were the means, but not the goal, of science. 'Not facts, then, but causes or principles are

\footnotetext{
${ }^{6}$ Note that the possibility of 'punctuated equilibria' with relatively rapid periods of evolutionary change does not undermine the principle of accumulation of 'slight, successive, favourable variations'; it simply means that the rate of accumulation can sometimes be relatively fast.
} 
the ultimate objects of scientific quest.' In another passage, Romanes explained that a goal of Darwinism was to extend the type of causal explanation that was applicable to mechanical phenomena into the organic world. Romanes (1893, p. 402) argued that Darwinism

seeks to bring the phenomena of organic nature into line with those of inorganic; and therefore to show that whatever view we may severally take as to the kind of causation which is energizing in the latter we must now extend to the former. ... the theory of evolution by natural selection ... endeavours to comprise all the facts of adaptation in organic nature under the same category of explanation as those which occur in inorganic nature - that is to say, under the category of physical, or ascertainable, causation.

Although it was widespread in the nineteenth century, it should not be assumed that the Darwin-Huxley-Romanes view of causation was universal. On the contrary, these Darwinists had to contend with the highly influential positivism of Auguste Comte (1853). Comte believed that science rested wholly on perceptible phenomena. David Hume had famously and rightly argued that events, but not causes, could be observed. Accordingly, for Comte - the supreme empiricist - the search after causes was futile, because they could not be discerned in our experience. Comte argued that such unobservables as causal connections were 'metaphysical' and beyond science. For Comte, science had to search for empirical regularities in order to derive laws.

The result was ironic. The Darwinians (with their emphasis on evolution) were opposed on one side by the creationists, acting in the name of religion. In addition, the Darwinians (with their emphasis on causation) were opposed on the other side by the stricter Comteans, acting in the name of science. From a strict Comtean perspective, Darwinism seemed to occupy a metaphysical no-man's-land between religion and science. However, in the second half of the nineteenth century, a philosophical alternative to Comtean positivism began to emerge, which was based on Darwinism. Its central tenet was that every event is determined in accordance with laws by something else. Furthermore, these laws are matters for scientific investigation.

Darwinism brought not only human evolution, but also the human mind and consciousness within the realms of science. Science proceeds by extending the domain of causal explanation. Much of human physiology could be explained by natural selection; Darwinism thus brought the frontier of scientific enquiry to the inner workings of the human mind.

\section{Darwinism Does Not Exclude Intentionality}

Another frequent objection to the use of these ideas in social science is that Darwinian evolution is 'blind' and ignores the conscious intentions and plans of human individuals. Famously, Edith Penrose (1952) argued that Darwinian theories of evolution excluded the deliberative and calculative behaviour that was characteristic of human action in the economic sphere. However, this hard-and-fast distinction between humans and other organisms is difficult to reconcile with the fact that humans evolved gradually from other species. If conscious intentions are unique to humans, then when and how in evolutionary time were these cognitive privileges bestowed upon humanity? To avoid a religious or mystical answer, we have to assume that these cognitive attributes themselves evolved through time, and existed to some degree in pre-human species. Although this proposition might itself be widely accepted, social scientists and others have often been reluctant to consider the causal origins on intentions themselves. 
As John Dewey (1910), Ernst Mayr (1988, 1992) and Daniel Dennett (1995) have argued, it is part and parcel of Darwin's underlying philosophy that all intention has itself to be explained by a causal process. This causal explanation has to show how the capacity to form intentions has itself gradually evolved in the human species, and also how individual intentions are formed in the psyche. For Darwin, natural selection is part of these causal explanations. There can be no 'uncaused cause'. However, the fact that intentions are somehow caused or determined does not mean that human agency is any less substantial or real (Vromen, 2001). Human intentions are part of social reality and social interactions involve human expectations concerning the intentions of others. None of these points is undermined by the recognition that intentions themselves are caused.

In principle, from a Darwinian philosophical perspective, all outcomes have to be explained in a linked causal process. There is no teleology or goal in nature. Everything must submit to a causal explanation in scientific terms. This is a key part of Darwin's ontological and theoretical outlook. As Dennett (1995, p. 205) reported, Darwin turned the traditional doctrine of intentionality upside down: 'intentionality doesn't come from on high; it percolates from below, from the initially mindless and pointless algorithmic processes that gradually acquire meaning and intelligence as they develop.' Much earlier, in his essay on the impact of Darwinism on philosophy, Dewey (1910, p. 15), made a similar point: 'Interest shifts ... from an intelligence that shaped things once for all to the particular intelligences which things are even now shaping'. Instead of God creating everything, the Darwinian focus is on how everything including human intelligence and intentionality were created through evolution. Intentionality is still active and meaningful, but it too has evolved over millions of years.

Accordingly, Penrose (1952) and others were wrong to suggest that Darwinian theories of evolution excluded deliberative and calculative behaviour. ${ }^{7}$ On the contrary, deliberation and selection are complementary mechanisms in the social context. Furthermore, as Darwin insisted, intentions, calculations and preferences have themselves to be explained by the methods of science. ${ }^{8}$ In his concern to explain descent with modification and the allencompassing 'tree of life' - as well as the emergence of humans and their intentions Darwin was persistently invoking a universal causal principle. Darwinism invokes both a theory of natural selection and a universal commitment to causal explanations. This brings us right back to the aforementioned central lacuna in social theory - the widespread failure to provide an adequate causal explanation of human intentionality and human motives.

Some theorists of social evolution believe that the 'Lamarckian' is preferable to the 'Darwinian' label because the former preserves human intentionality. There is a deep irony here, sometimes based on ignorance of the work of Lamarck himself. Lamarck himself was a philosophical materialist and saw intention or volition as rooted in material causes (Boesiger, 1974). In addition, to repeat, there is nothing on Darwinism that excludes or undermines the reality of human purposes and intentions.

A further objection may be that the explanation of human motives denies the reality of choice. This objection will be discussed further below. At this stage, it is pointed out that

\footnotetext{
${ }^{7}$ In conversations with the present author before her death in 1996, Penrose had revised her opinion. She was deeply fascinated with evolutionary and other explanations of human consciousness. She did not take human deliberation as given or for granted.

8 This admits the possibility that one science (say economics) might take preferences as given while others (say biology, psychology or sociology) might attempt to explain those preferences. Further arguments would be necessary to counter this compartmentalized view.
} 
causal determination of choices does not imply an absence of the subjective awareness of choice. Neither does it imply that choice is unreal. Very small causal influences can have big effects and can thus cause the individual to act otherwise. ${ }^{9}$ Finally, the notion that choice or any other phenomenon is uncaused is unacceptable, for reasons explored later.

It is not being argued here that every theory or explanation in the social sciences has to include an explanation of the motives or preferences of the individuals involved. No theory can explain everything. For some purposes and in some circumstances, it can be legitimate to take the purposes or preferences of the individuals involved as given. All theories involve abstractions. In some cases it can be legitimate to abstract from the influences on, and changes in, individual preferences and purposes. In which case, human intentions become the elemental forces in the particular theoretical explanation. But even in this case, the assumptions concerning human intentions should be consistent with what we know about human evolution and individual development. Furthermore, the use of a simplifying assumption in one theory does not rule out the need for another theory to explain those elements that are taken as constant or given. Intentions and preferences still have to be explained at some stage.

Darwinians have pointed to reasons why consciousness and intention had themselves evolved. As Romanes (1883, p. 272) argued, the evolutionary advantage of intention and judgement in consciousness organisms was 'probably that of supplying to natural selection variations of ancestral instincts which are not merely fortuitous, but intentionally adapted to the conditions of the environment'. Conscious reflection on novel circumstances and behavioural choices could provide a better evaluation of threats and opportunities. It could lead to behaviour that enhanced the organism's chances of survival. This in turn would lead to the selection of organisms that were more skilled in their conscious deliberations. These behavioural problems would be further enlarged within social structures with rules concerning individual interactions (Cummins, 1998), and with the development of the manipulative and tool-using skills that were dependent on bipedalism (Bronowski, 1973; Childe, 1951). All these environmental factors, social interactions and manipulative capacities would promote further mental development through natural selection.

\section{Is Darwinism 'Mechanistic' or 'Deterministic'?}

Some social scientists may react with the accusation that the argument here is 'mechanistic' or 'deterministic'. But the social sciences are satiated with rebuttals of 'mechanistic' and 'deterministic' doctrines, where these doctrines are themselves poorly defined. Others, in contrast, enthusiastically take up the idea that human beings are 'mere machines', as a warrant for their version of scientific enquiry. Others see this 'mere machines' statement as a sufficient condemnation of the approaches involved. Yet rarely is the 'mere machines' idea clarified and explored further. Both enthusiasts and critics fail to adequately define their terms.

Clearly the statement that human beings are 'mere machines' is wrong in existing technological terms; no machine has yet been built with the capacity for self-reflection and consciousness. We do not know if would be possible to build such a machine in the future.

\footnotetext{
${ }^{9}$ I am aware that I am skipping over a very big problem in philosophy here, which itself has a huge and controversial literature. Some of my further thoughts are in Hodgson (2004), with references to part of that literature.
} 
Consider the words of Richard Dawkins (1976, 1986), who is fond of describing organisms and humans as mere 'robots' or 'machines'. This is meant to be provocative. But all shock and explanatory value is lost when it is realised that Dawkins does not explain adequately what a machine is. He admits that humans have consciousness and purpose, but with minimal exploration of the meaning of these terms. As with the opponents of 'mechanistic' doctrines, rhetoric triumphs over substance.

Among those social scientists that emphasise consciousness and choice, things are only slightly better. Economists typically make a song and dance about choice. But only the maverick economists reflect upon its definition (Shackle, 1976; Buchanan, 1969; Loasby, 1976; Lawson, 1997). Sociologists write of human agency and self-reflection, but the underlying presuppositions are as yet inadequately explored.

To proceed further, some definitions must be attempted. A provisional working definition of a 'mechanism' is a structure involving causal connections but lacking an adequate capacity for self-reflection, intentionality or will. We may or may not see intentionality in non-human organisms. Intentionality requires the capacity to prefigure a goal in conscious thought; but these terms themselves require further refinement. But we may leave these important issues concerning the nature and extent of intentionality on one side. It is already clear, with this rough definition of a mechanism, that the Darwinian theoretical approach embraced here is not mechanistic. It is simply asserted here that human intentionality is itself caused, and in turn it requires some causal explanation.

In contrast, despite its verbal emphasis on 'choice', much of mainstream economics is mechanistic in the sense of lacking adequate notions of human self-reflection, intelligence, intentionality or will. This is because human agents are often modelled as automata, with limited cognitive or learning capacities, reacting crudely to stimuli from their environment that are somehow unambiguous. To overcome the limitations of mechanistic models of human agency, significant attention must be given to factors such as the number and complexity of stimuli, cognitive processes, interpretative ambiguity, and so on.

Other writers see the term mechanistic as denoting an emphasis on quantitative rather than qualitative factors of change. This is a very different meaning of this word. But again, the approach adopted in the present work is not mechanistic, even in this alternative sense. Both qualitative as well as quantitative changes are emphasised here. Still other writers associate 'mechanistic' with an atomistic ontology, in which entities are said to possess qualities independently of their relations with other entities. But again, the approach adopted here is not mechanistic in this sense.

The Darwinian ideas that every event has a cause, and that even human motivations have to be subjected to causal explanation, will provoke in some quarters the accusation of 'determinism'. This too is misleading and in some senses mistaken. The very word 'determinism' connotes a confusing multiplicity of meanings. Essentially, there are at least three different versions of 'determinism', as briefly described below.

(1) Determinism is sometimes defined as the epistemological doctrine that 'any event can be rationally predicted, with any desired degree of precision, if we are given a sufficiently precise description of past events, together with all the laws of nature' (Popper, 1982, pp. 1-2). We may call this idea 'predictability determinism'.

(2) A different definition of determinism is the notion that, any given set of circumstances and state of the world must lead to a unique outcome: 'given $A, B$ must occur' (Blanshard, 1958, p. 20). We may call this principle 'regularity determinism'. It involves a denial of 
randomness and chance in the universe. This is an ontological rather than an epistemological notion: it says nothing about what we may be able to know or predict.

(3) Another definition of determinism is the notion that every event has a cause (Urmston, 1989). This is again an ontological statement about the world, otherwise known in philosophy as ‘the principle of universal causation' or sometimes 'ubiquity determinism'. Bunge (1959, p. 26) provided a more refined formulation. He described the 'principle of determinacy' amounting to: 'Everything is determined in accordance with laws by something else'.

The third version of 'determinism', which is better described as the principle of determinacy, is central to Darwinism and it is adopted here. ${ }^{10}$ But there is nothing in Darwinism that involves any commitment to the first two versions of determinism. Furthermore, these three versions of determinism are logically independent: one does not flow from the other. Mario Bunge (1959), Roy Bhaskar (1975), John Earman (1986) and Sunny Auyang (1998) have rightly argued that predictability determinism is quite different from the third principle, of determinacy or universal causation. Predictability determinism - the dream of Laplace - is itself countered by the realisation of analytical and computational limits in the face of complexity, and even of the limits of mathematics itself (Gödel's Proof), and more recently by theories of computability, chaos and complexity. There are non-linear systems with such a high degree of sensitivity to initial conditions that no amount of accurate measurement of the appropriate parameter values can provide a sufficiently accurate prediction (the Butterfly Effect). Predictability in the human domain is also confounded by the logical problem of predicting future knowledge or creativity. If prediction led us to know future knowledge, then it would be present knowledge, not knowledge confined to the future (Popper, 1960, 1982).

As formulated above, the third proposition of law-like determination itself does not rule out the possibility of statistical determination, where outcomes are stochastic but with regular statistical properties. Statistical laws are still laws. If outcomes were statistically determined, and statistical determination was not merely apparent but real, then the second proposition regularity determinism - would strictly and generally be false. But the third proposition would not be undermined.

Even if determination is not statistical but links one set of causes with one set of effects, then there are still objections to regularity determinism. Roy Bhaskar (1975) rightly rejects regularity determinism on the grounds that it would work only if it were confined to a closed system, and most systems are in fact open. The possibility of exogenous disturbances undermines regularity determinism in specific systems.

Would regularity determinism apply to the universe as a whole? Given that the universe is interconnected and systems are open, the regularity 'given $A, B$ must occur' would only work in general if $A$ corresponded to a complete description of all the possible influences on $B$, from throughout the universe. The statement 'given $A, B$ must occur' will itself be indescribable in its massive scope and complexity. Strictly, with unlimited interconnectedness, the 'given $A, B$ must occur' statement will only pertain if $A$ is a complete description of the state of the universe. Even if we exclude a possible indeterminacy in nature - such as at the quantum level - the idea of regularity determinism cannot apply to any limited description of the world. No manageable form of the statement 'given $A, B$ must

10 Note the difference with Hodgson (1993) where I was equivocal over the adoption of the principle of determinacy. I was then needlessly worried that this principle might be incompatible with free will and genuine choice. 
occur' can sustain regularity determinism. In terms of any conceivable human discourse, regularity determinism is generally inapplicable. Even if it is valid, it is inapplicable as a principle. In sum, regularity determinism is inapplicable or false.

Having rejected or disabled the first two versions of determinism, the (third) principle of determinacy is retained. Indeed, it is a necessary foundation for science. The theological definition of a miracle is something that happens without an identifiable cause. If science admits the possibility of an event without a cause, then it has abandoned its own mission. We can have quite a broad view of the nature of science, but the quest for meaning and explanation seems indispensable to any version of the scientific enterprise. In contrast, the idea of an uncaused cause forsakes the possibility of an intelligent account or explanation of the event. Of course, we cannot prove the impossibility of an uncaused cause. In general, proofs of causality, or of its absence, are impossible. But science is nevertheless obliged to search for causal explanations, and determinacy must hence be assumed. In many circumstances, prediction will be impossible. Nevertheless, the quest for some kind of causal explanation must remain. To adopt the notion of an uncaused cause is to issue a licence to abandon the quest.

Darwinism is thus incompatible with the idea of George Shackle (1976) that human intentionality is an 'uncaused cause'. A problem with Shackle's position is that it involves an investigatory closure. Once we affirm an 'uncaused cause' we say that science should explain this much, but no more. We may move so far down the causal chain, but no further. We arrive at a causal and explanatory roadblock, policed by the adherents of the 'uncaused cause'. Admittedly, all ontological commitments involve dogma in the sense that they cannot be directly verified by experience. But the principle of determinacy is preferable to the 'uncaused cause' in that it does not place dogmatic bounds on the scope of scientific enquiry and explanation. The preferable ontological commitment is one that rules out miracles and denies any no-go zones for science. The roadblock must be opened, even if the road ahead is treacherous and complex. ${ }^{11}$

Strictly, we can prove neither the presence nor the absence of a cause. The argument in the preceding paragraph does not prove the impossibility of an uncaused cause. It simply demonstrates that of the two alternative assumptions - the existence or otherwise of an uncaused cause - the assumption of that all phenomena are caused is preferable because it does not place limits to enquiry. This applies to human will and choice, as well as to other phenomena. We may not find the cause, but in which case it is better to leave the matter open, rather than proclaiming an uncaused cause.

But if our choices are determined, how could we have acted otherwise? Choice may be seen to lack substance of no alternative could have been chosen. In response, the above argument can be expanded to deal with this objection that the principle of determinacy denies the reality of choice. The philosophical problem of free will is to complex to be discussed adequately here but some preliminary points of response can be mentioned. Regularity determinism has been undermined above. Crucially, two situations of choice are never identical in all details. Even if two situations are very similar, we could act differently because of slight influences with sufficiently magnified effects. For instance, the very fact that we are reflecting upon the

11 My own position has changed on this issue. Hodgson (1993) failed to decisively reject the notion of an uncaused cause. However, I also noted that chaos theory suggests that even if the world is deterministic, it may appear as entirely spontaneous and free. I now believe that the admission of the possibility of an uncaused cause is not only unnecessary but also untenable, for the reasons given here. 
possibility of 'acting otherwise' may be sufficient for us to make a different choice. Complexity, emergence and sensitivity make choice real, despite the fact that it is determined.

Some authors argue that if our will is determined then we can hardly be held responsible for our choices and our actions. It is alleged that as a result of such 'determinism' there can be no basis for morality or law. Two brief responses are appropriate here. First, if our will is determined, then moral pressure and legal sanctions still have an effect on our actions. Consequently, there is no ground for abandoning morality or law. Second, even if, on the contrary, our will was an 'uncaused cause', then we would be no more responsible for the capricious and spontaneous processes that led to our actions. The 'uncaused cause' adds nothing extra to the importance of morality or law. They are important in any case.

For example, a philosophically minded murderer might claim that his decision to pull the trigger of his gun was caused by events beyond his control. Another might claim that her intention to murder appeared spontaneously in her mind. The first murderer is just as responsible for the murder as the second. In both cases the prosecution would argue that the (caused or uncaused) inclination to kill should have been resisted and countered within the mind of the murderer, so that the murder did not take place. The principle of determinacy does not remove the burden or possibility of individual responsibility.

The position adopted here does not rule out some notions of novelty, nor even of 'free will'. A number of philosophers - including David Hume and Jean-Paul Sartre - have argued that an idea of free will is compatible with the principle of determinacy. Even if our choices are determined then that does not rule out the reality of the process of choice. In philosophy, this position is known as 'compatibilism'. The Darwinian position stated here admits ground for the 'compatibilist' argument that 'choice' and 'free will' can be reconciled with the proposition that every event is determined. ${ }^{12}$

If novelty simply refers to unpredicted outcomes then we have no difficulty admitting such possibilities, even if every event is caused. We now know from chaos theory that even if every event is determined, the world is still often unpredictable. Randomness and apparent indeterminacy remain. Novelty may be caused, but it will often appear as entirely spontaneous and free. Prior causes always exist, but the complexity of the system may make them especially difficult to identify. In open, complex, non-linear systems all sorts of novelties are possible. What are ruled out of the picture are novel outcomes that do not themselves obey actual scientific laws. ${ }^{13}$

\section{Conclusion: Some Darwinian Philosophical Principles for the Social Sciences}

Darwinism is rightly associated with the ideas of variation, inheritance and selection. However, underlying this theory of evolution are philosophical principles that are even more fundamental to Darwinism. At this point it would be useful to clarify and take stock of some of these principles, which derive from the discussion above. There are additional

\footnotetext{
12 It is beyond the scope of this essay to probe compatibilism further. Among the many works on this topic see Sterba and Kourany (1981), Dennett (1984), Honderich (1993) and Vromen (2001).

13 On the compatibility of novelty with the principle of determinacy see Bunge (1959, ch, 8). Vromen (2001) rightly argues that evolutionary theory cannot be rejected on the grounds that it fails to predict novelty. Much of that which is described as novelty is unpredictable by any theory.
} 
philosophical principles within Darwinism, but the discussion of these must be left to another work.

(1) The principle of determinacy. This is otherwise known in philosophy as 'the principle of universal causation' or sometimes 'ubiquity determinism'. Its rough and ready expression is 'every event has a cause', and more precisely, everything is determined in accordance with laws by something else.

The basis for the principle of determinacy has been elaborated above. It does not imply that events are necessarily predictable, or that any one set of events will always lead to the same, regular outcome. These versions of 'determinism' are not adopted here. Furthermore, the principle of determinacy does not imply a 'mechanistic' view. Such a 'mechanistic' view is said to exclude intentionality, but intentionality and will are here included. The principle of determinacy upholds that intentions are caused, but this does not diminish the reality or responsibility of will or choice. The opposite and unacceptable view of an uncaused cause would not make us responsible for our actions, as they would result from capricious and spontaneous processes beyond our knowledge and control.

(2) The doctrine of continuity. As noted above, this phrase was promoted by Huxley to capture the Darwinian ideas that a species is a causal and evolutionary outcome of accumulated gradations and variations, with organisms that inherit and preserve most of their characteristics through time. More generally, it is upheld that complex outcomes are the result of accumulated, incremental changes. Destiny, miraculous leaps and teleological determination are excluded. This means that human intentionality has itself evolved gradually through time. In general, continuity involves mechanisms of inheritance upon which slight generational variations are superimposed and accumulated. Darwin's treatment of inheritance is thus grounded on this principle.

(3) Cumulative causal explanation. As explained above, Darwinism involves the idea of searching for causal explanations of these step-by-step developments. Accordingly, their explanation involves tracing this causal process by focusing on its key processual algorithms. Even if every step in the process cannot be determined in detail; the exploration of the algorithmic process itself helps to provide an explanation. The key algorithmic process emphasised by Darwin was natural selection. Hence Darwin's theory of natural selection is partly built on this principle. However, as emphasised elsewhere (Hodgson, 2004), the concept of selection in Darwinism necessarily invokes neither competition nor militant struggle.

There are other Darwinian ontological principles that there is not the space to explore here. Among these are Darwin's 'population thinking' (Mayr, 1964, 1988, 1992) and an approach that Bunge (1980) has described as 'emergentist materialism'. Emergentist materialism rejects multiple and independent forms of being, where one type of substance (notably mind) is treated as entirely separate from and independent of another (notably matter); the mental level is understood in terms of emergent properties of organised matter.

What has been argued here is that Darwinism itself presupposes several important ontological presuppositions, in particular concerning causality. These presuppositions apply to the socio-economic as well as the biological realm.

Geoffrey M. Hodgson 
g.m.hodgson@herts.ac.uk

$-14-$ 


\section{References}

Auyang, Sunny Y. (1998) Foundations of Complex-System Theories: In Economics, Evolutionary Biology, and Statistical Physics (New York and Cambridge: Cambridge University Press).

Barrett, Paul H., Gautrey, Peter J., Herbert, Sandra, Kohn, David and Smith, Sydney (eds) (1987) Charles Darwin's Notebooks, 1836-1844: Geology, Transmutation of Species, Metaphysical Enquiries (Cambridge: Cambridge University Press).

Bhaskar, Roy (1975) A Realist Theory of Science, $1^{\text {st }}$ edn. (Leeds: Leeds Books).

Blanshard, Brand (1958) ‘The Case for Determinism’ in Hook, Sidney (ed.) (1958) Determinism and Freedom in the Age of Modern Science (New York and London: Collier Macmillan), pp. 19-30.

Boesiger, Ernest (1974) ‘Evolutionary Theories after Lamarck and Darwin’ in Ayala, Francisco J. and Dobzhansky, Theodosius (eds) (1974) Studies in the Philosophy of Biology (London, Berkeley and Los Angeles: Macmillan and University of California Press), pp. 21-44.

Bronowski, Jacob (1973) The Ascent of Man (Boston: Little Brown).

Buchanan, James M. (1969) 'Is Economics the Science of Choice?', in Erich Streissler (ed.) (1969) Roads to Freedom: Essays in Honour of Friedrich A. von Hayek (London: Routledge and Kegan Paul), pp. 47-64.

Bunge, Mario A. (1959) Causality: The Place of the Causal Principle in Modern Science (Cambridge, MA: Harvard University Press).

Bunge, Mario A. (1980) The Mind-Body Problem: A Psychobiological Approach (Oxford: Pergamon).

Campbell, Donald T. (1965) 'Variation, Selection and Retention in Sociocultural Evolution', in Barringer, H. R., Blanksten, G. I. and Mack, R. W. (eds) (1965) Social Change in Developing Areas: A Reinterpretation of Evolutionary Theory (Cambridge, MA: Schenkman), pp. 19-49. Reprinted in General Systems, 14, 1969, pp. 69-85.

Childe, V. Gordon (1951) Man Makes Himself (New York: Mentor).

Churchland, Patricia S. (1986) Neurophilosophy: Toward a Unified Science of the Mind-Brain (Cambridge, MA: MIT Press).

Churchland, Paul M. (1984) Matter and Consciousness (Cambridge, MA: MIT Press).

Churchland, Paul M. (1989) A Neurocomputational Perspective: The Nature of Mind and the Structure of Science (Cambridge, MA: MIT Press).

Comte, Auguste (1853) The Positive Philosophy of Auguste Comte, 2 vols., translated by Harriet Martineau from the French volumes of 1830-42 (London: Chapman).

Cummins, Denise Delarosa (1998) 'Social Norms and Other Minds' in Cummins, Denise D. and Allen, Colin (eds) (1998) The Evolution of Mind (Oxford and New York: Oxford University Press), pp. 30-50.

Cushing, James (1994) Quantum Mechanics: Historical Contingency and the Copenhagen Hegemony (Chicago: Chicago University Press). 
Darwin, Charles R. (1859) On the Origin of Species by Means of Natural Selection, or the Preservation of Favoured Races in the Struggle for Life, first edn. (London: Murray).

Darwin, Charles R. (1871) The Descent of Man, and Selection in Relation to Sex, 1st edn., 2 vols (London: Murray and New York: Hill).

Darwin, Charles R. (1883) The Variation of Animals and Plants Under Domestication, 2 vols., $2^{\text {nd }}$ edn. (London and New York: Murray and Appleton).

Dawkins, Richard (1976) The Selfish Gene (Oxford: Oxford University Press).

Dawkins, Richard (1983) 'Universal Darwinism’, in D. S. Bendall (ed.) (1983) Evolution from Molecules to Man (Cambridge: Cambridge University Press), pp. 403-25.

Dawkins, Richard (1986) The Blind Watchmaker (Harlow: Longman).

Dennett, Daniel C. (1984) Elbow Room: The Varieties of Free Will Worth Wanting (Cambridge, MA: MIT Press).

Dennett, Daniel C. (1995) Darwin's Dangerous Idea: Evolution and the Meanings of Life (London: Allen Lane).

Dewey, John (1910) The Influence of Darwin on Philosophy and Other Essays in Contemporary Philosophy (New York: Holt).

Earman, John (1986) A Primer on Determinism (Boston: Reidel).

Einstein, Albert, Podolsky, Boris and Rosen, Nathan (1935) 'Can Quantum-Mechanical Descriptions of Physical Reality be Considered Complete?’, Physical Review, 47, pp. 77780 .

Gould, Stephen Jay (1978) Ever Since Darwin: Reflections in Natural History (London: Burnett Books).

Hodgson, Geoffrey M. (1993) Economics and Evolution: Bringing Life Back Into Economics (Cambridge, UK and Ann Arbor, MI: Polity Press and University of Michigan Press).

Hodgson, Geoffrey M. (2001a) 'Is Social Evolution Lamarckian or Darwinian?' in Laurent, John and Nightingale, John (eds) (2001) Darwinism and Evolutionary Economics (Cheltenham: Edward Elgar), pp. 87-118.

Hodgson, Geoffrey M. (2001b) 'Darwin, Veblen and the Problem of Causality in Economics', History and Philosophy of the Life Sciences, 23, pp. 383-422.

Hodgson, Geoffrey M. (2002) 'Darwinism in Economics: From Analogy to Ontology', Journal of Evolutionary Economics, 12(2), June, pp. 259-81.

Hodgson, Geoffrey M. (2003) 'The Mystery of the Routine: The Darwinian Destiny of An Evolutionary Theory of Economic Change’, Revue Économique, 54(2), Mars, pp. 355-84.

Hodgson, Geoffrey M. (2004) The Evolution of Institutional Economics: Agency, Structure and Darwinism in American Institutionalism (London and New York: Routledge).

Honderich, Ted (1993) How Free Are You? (Oxford: Oxford University Press).

Huxley, Thomas Henry (1894) Collected Essays, 9 vols (London: Macmillan).

Knudsen, Thorbjørn (2004) 'General Selection Theory and Economic Evolution: The Price Equation and the Genotype/Phenotype Distinction’, Journal of Economic Methodology, this issue. 
Lawson, Tony (1997) Economics and Reality (London: Routledge).

Loasby, Brian J. (1976) Choice, Complexity and Ignorance: An Enquiry into Economic Theory and the Practice of Decision Making (Cambridge: Cambridge University Press).

Mayr, Ernst (1964) 'Introduction', in facsimile of the first edition of Darwin, Charles R. (1859) On the Origin of Species by Means of Natural Selection, or the Preservation of Favoured Races in the Struggle for Life (London: Murray), pp. vii-xxvii.

Mayr, Ernst (1988) Toward a New Philosophy of Biology: Observations of an Evolutionist (Cambridge, MA and London: Harvard University Press).

Mayr, Ernst (1992) One Long Argument: Charles Darwin and the Genesis of Modern Evolutionary Thought (London: Allen Lane).

Nelson, Richard R. and Winter, Sidney G. (1982) An Evolutionary Theory of Economic Change (Cambridge, MA: Harvard University Press).

Penrose, Edith T. (1952) 'Biological Analogies in the Theory of the Firm', American Economic Review, 42(4), December, pp. 804-19.

Popper, Karl R. (1960) The Poverty of Historicism (London: Routledge and Kegan Paul).

Popper, Karl R. (1982) The Open Universe: An Argument for Indeterminism, from the Postscript to the Logic of Scientific Discovery, edited by William W. Bartley, III (London: Hutchinson).

Ritchie, David G. (1896) 'Social Evolution’, International Journal of Ethics, 6(2), pp. 165-81.

Romanes, George John (1883) Mental Evolution in Animals (London: Kegan Paul, Trench).

Romanes, George John (1893) Darwin and After Darwin: An Exposition of the Darwinian Theory and a Discussion of Post-Darwinian Questions, vol. 1, 2nd edn. (London: Longmans, Green).

Rosenberg, Alexander (1995) The Philosophy of Social Science, $2^{\text {nd }}$ edn. (Boulder, CO: Westview Press).

Runde, Jochen H. (1998) ‘Assessing Causal Economic Explanations’, Oxford Economic Papers, 50(1), pp. 151-72.

Ruse, Michael (1979) The Darwinian Revolution: Science Red in Tooth and Claw, $1^{\text {st }}$ edn. (Chicago: University of Chicago Press).

Salmon, Wesley C. (1998) Causality and Explanation (Oxford: Oxford University Press).

Shackle, George L. S. (1976) 'Time and Choice', Proceedings of the British Academy, 66, pp. 309-29. Reprinted in Shackle, George L. S. (1990) Time, Expectations and Uncertainty in Economics: Selected Essays of G. L. S. Shackle, ed. J. L. Ford (Aldershot: Edward Elgar).

Sosa, Ernest and Tooley, Michael (eds) (1993) Causation (Oxford: Oxford University Press).

Sterba, James P. and Kourany, Janet A. (1981) 'How to Complete the Compatibilist Account of Free Action’, Philosophy and Phenomenological Research, 41(4), June, pp. 508-23.

Stewart, Ian (1989) Does God Play Dice? The Mathematics of Chaos (Oxford: Basil Blackwell).

Stich, Stephen P. (1983) From Folk Psychology to Cognitive Science (Cambridge, MA: MIT Press). 
Urmston, J. O. (1989) 'Determinism', in Urmston, J. O. and Rée, Jonathan (eds) (1989) The Concise Encyclopedia of Western Philosophy and Philosophers (London: Unwin Hyman), p. 78.

Veblen, Thorstein B. (1919) The Place of Science in Modern Civilization and Other Essays (New York: Huebsch).

Vromen, Jack J. (2001) 'The Human Agent in Evolutionary Economics', in Laurent, John and Nightingale, John (eds) (2001) Darwinism and Evolutionary Economics (Cheltenham: Edward Elgar), pp. 184-208.

Witt, Ulrich (2004) 'Evolutionary Economics and the Extension of Evolution to the Economy', Journal of Economic Methodology, this issue. 